\title{
Oral tolerance in the absence of naturally occurring Tregs
}

\author{
Daniel Mucida, ${ }^{1,2}$ Nino Kutchukhidze, ${ }^{1}$ Agustin Erazo, ${ }^{1}$ Momtchilo Russo, ${ }^{2}$ \\ Juan J. Lafaille,1,3 and Maria A. Curotto de Lafaille,

\begin{abstract}
1Program of Molecular Pathogenesis, Skirball Institute of Biomolecular Medicine, New York University School of Medicine, New York, New York, USA. ${ }^{2}$ Departmento de Imunologia, Universidade de São Paulo, São Paulo, Brazil. ${ }^{3}$ Department of Pathology, New York University School of Medicine, New York, New York, USA.
\end{abstract}

\begin{abstract}
Mucosal tolerance prevents pathological reactions against environmental and food antigens, and its failure results in exacerbated inflammation typical of allergies and asthma. One of the proposed mechanisms of oral tolerance is the induction of Tregs. Using a mouse model of hyper-IgE and asthma, we found that oral tolerance could be effectively induced in the absence of naturally occurring thymus-derived Tregs. Oral antigen administration prior to i.p. immunization prevented effector/memory Th2 cell development, germinal center formation, class switching to IgE, and lung inflammation. Oral exposure to antigen induced development of antigen-specific $\mathrm{CD}^{+} \mathrm{CD} 25^{+} \mathrm{Foxp} 3^{+} \mathrm{CD} 45 \mathrm{RB}^{\text {low }}$ cells that were anergic and displayed suppressive activity in vivo and in vitro. Oral tolerance to the Th2 allergic response was in large part dependent on TGF- $\beta$ and independent of IL-10. Interestingly, Tregs were also induced by single i.p. immunization with antigen and adjuvant. However, unlike oral administration of antigen, which induced Tregs but not effector $T$ cells, i.p. immunization led to the simultaneous induction of Tregs and effector Th2 cells displaying the same antigen specificity.
\end{abstract}

\section{Introduction}

Oral tolerance can be defined as an inhibition of specific immune responsiveness to subsequent parenteral injections of proteins to which an individual or animal has been previously exposed via the oral route (1-4). Several mechanisms have been proposed for the development of oral tolerance, ranging from the deletion of antigen-specific T cells $(5,6)$ to immune deviation $(7,8)$, induction of anergy (9), and suppression by Tregs $(10,11)$.

When markers of naturally occurring Tregs, such as CD45RB low, CD25, cytotoxic T lymphocyte-associated antigen 4 (CTLA-4), glucocorticoid-induced TNF receptor (GITR), and, more recently, the forkhead box transcription factor Foxp3 became available, a number of studies described a role for naturally occurring Tregs in the development of oral or inhaled tolerance (10-17). However, these studies did not address the issue of whether naturally occurring Tregs are necessary for the induction of oral tolerance.

The possible role of Tregs as mediators of oral tolerance has been addressed by directly feeding antigen to TCR-transgenic mice $(10,11,18)$ and by using TCR transgenic mice as a source of naive antigen-specific T cells in transfer systems $(11,14,15)$. In all these experimental systems, the influence of thymic-derived naturally occurring Tregs could not be ruled out, either because the studies were carried out in TCR transgenic recombination activating gene $\left(\mathrm{RAG}^{+}\right)$systems or because antigen-specific $\mathrm{T}$ cells were transferred to wild-type mice, which have a full complement of naturally occurring Tregs. The influence of these host-derived Tregs on

Nonstandard abbreviations used: BAL, bronchoalveolar lavage; CTLA-4, cytotoxic T lymphocyte-associated antigen 4; GITR, glucocorticoid-induced TNF receptor; GC, germinal center; Imm, mice given OVA-HA i.p. immunization; $\mathrm{mLN}$, mesenteric lymph node; Oral, mice fed OVA in drinking water; RAG, recombination activating gene; Th3 cell, TGF- $\beta$-producing Treg cell; Tol, mice fed OVA in drinking water prior to OVA-HA i.p. immunization.

Conflict of interest: The authors have declared that no conflict of interest exists.

Citation for this article: J. Clin. Invest. 115:1923-1933 (2005).

doi:10.1172/JCI24487. the behavior of the antigen-specific TCR transgenic T cells could not be assessed. It has been shown that TCR transgenic RAG ${ }^{+}$mice harbor antigen-specific Tregs, but virtually all of these Tregs coexpress 1 or 2 TCR chains encoded by endogenous TCR genes. It is believed that endogenous TCR chains are essential for the thymic differentiation of antigen-specific TCR transgenic Tregs, which are absent in most TCR transgenic $\mathrm{RAG}^{-/-}$mice (19).

It has become increasingly apparent in the past several months that cells indistinguishable from naturally occurring thymicderived $\mathrm{CD}^{+} \mathrm{CD} 25^{+} \mathrm{Foxp}^{+}$Tregs can be generated in vivo in the periphery of experimental animals. The peripheral conversion of naive $\mathrm{CD} 4^{+} \mathrm{CD} 25^{-} \mathrm{T}$ cells from TCR-transgenic $\mathrm{RAG}^{-/-}$mice into functional antigen-specific $\mathrm{CD} 4^{+} \mathrm{CD} 25^{+} \mathrm{Foxp} 3^{+}$Tregs was shown by Apostolou and von Boehmer, after s.c. infusion of the TCR transgene-specific peptide ligand (20), and by Cobbold et al., after sex-mismatched skin grafting performed together with coreceptor blockade (21). We have shown that about $10-15 \%$ of naive $\mathrm{CD}^{+} \mathrm{CD} 25^{-} \mathrm{Foxp}^{-} \mathrm{T}$ cells convert into functional $\mathrm{CD}^{+}{ }^{+} \mathrm{CD} 25^{+} \mathrm{Foxp}^{+}$Tregs upon homeostatic proliferation (22). In addition to these examples of Tregs that are very similar to thymicderived naturally occurring Tregs, it has been known for some time that regulatory cells displaying a range of differences from naturally occurring Tregs could be generated in vivo in peripheral tissues. For instance, $\mathrm{CD} 8^{+} \mathrm{DCs}$ isolated from mice immunized with heat-killed Listeria monocytogenes induced Tregs that display some Th1 properties (23). Immunization with certain GAD65 peptides led to the development of cells that resemble Tr1 Tregs (24). Administration of myelin basic protein peptides i.n. also resulted in the generation of IL-10-producing Tregs (25), which are Foxp3 negative (26). Epicutaneous immunization was shown to induce $\mathrm{CD} 4^{+} \mathrm{CD} 25^{-}$Tregs (27). Importantly, oral administration led to the generation of TGF- $\beta$-producing Treg (Th3) cells (28). Finally, in vitro approaches have demonstrated that naive $T$ cells activated in the presence of TGF- $\beta$ generate $\mathrm{CD} 4^{+} \mathrm{CD} 25^{+} \mathrm{Foxp} 3^{+}$Tregs that resemble naturally occurring Tregs (29-31). 
A

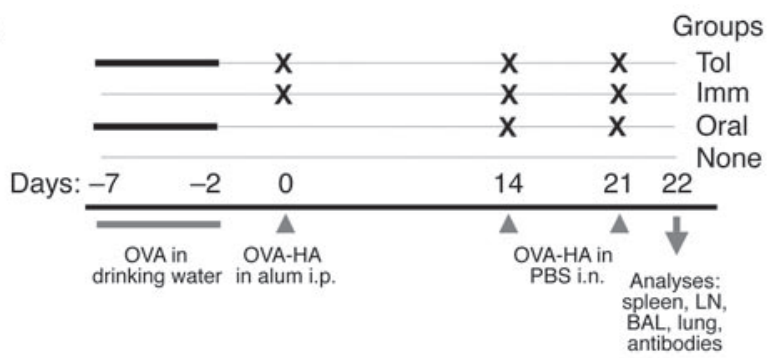

B
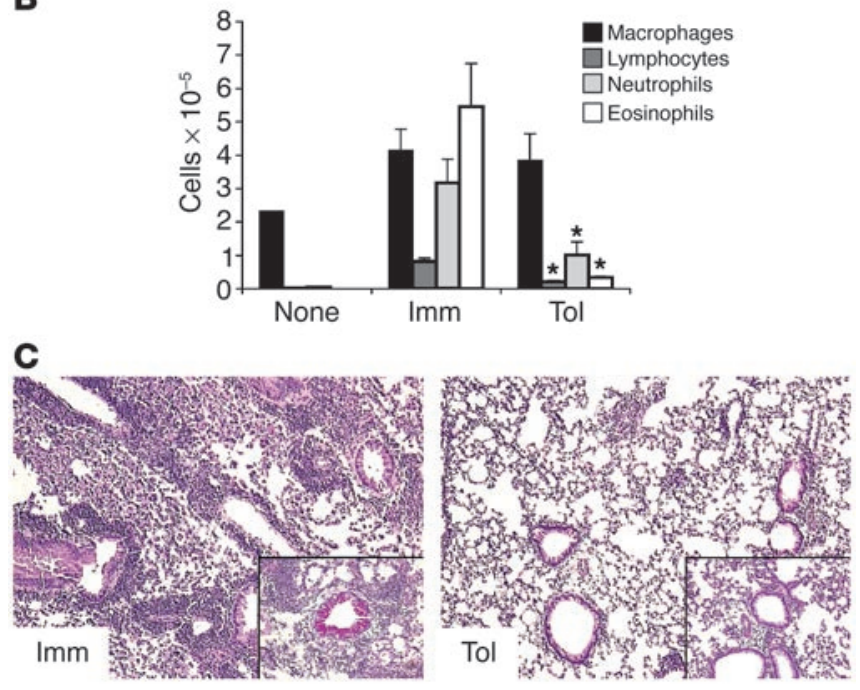

Using an experimental asthma model, we here show that mice devoid of naturally occurring Tregs are highly susceptible to the induction of oral tolerance after being fed antigen in drinking water. Oral antigen administration impairs the development of effector/memory Th2 cells and germinal centers (GC), class switching to $\mathrm{IgE}$, and lung inflammation. Moreover, oral exposure to antigen leads to the generation of peripheral antigenspecific $\mathrm{CD} 4{ }^{+} \mathrm{CD} 25^{+} \mathrm{CD} 45 \mathrm{RB}^{\text {low }}$ Tregs that express Foxp3 and CTLA-4. Our results demonstrate that oral tolerance induction does not require naturally occurring thymus-derived Tregs, as

\section{Figure 1}

Antigen feeding suppresses an asthma-type inflammatory response in T/B monoclonal mice. (A) Tolerization protocol and experimental groups. Groups of 5 T/B monoclonal mice were administered a $1 \%$ OVA solution in drinking water for 5 consecutive days (days -7 to -2 ). Two days later, the mice were immunized i.p. with $100 \mu \mathrm{g}$ of OVA-HA in alum (day 0). Fourteen and 21 days after immunization, the mice were challenged with $10 \mu \mathrm{g}$ of OVA-HA i.n. Twenty-four hours later (day 22), the sera, BAL cells and fluid, lymphoid organs, and lungs were harvested for analysis. The results shown in Figures 1 and 2 are representative of 5 experiments. None, untreated mice. (B) BAL cells were collected on day 22, and differential counts were performed in cytospin preparations. Results are expressed as mean \pm SEM. *Significant differences were found $(P<0.05)$ between values of Tol and Imm groups. (C) Representative lung sections were stained with H\&E (large pictures) or PAS/hematoxylin (insets) to analyze lung parenchyma inflammation and production of mucus by Goblet cells. Note the intense cellular infiltrate and mucus production in the Imm sample (left panels) and the suppression of inflammation in the Tol sample (right panels).

functional Tregs of similar characteristics are induced by oral antigen administration.

\section{Results}

OVA feeding suppresses asthma-like responses in the absence of naturally occurring thymus-derived Tregs. We sought to determine whether oral tolerance to an allergic response could be induced in the absence of thymus-derived Tregs. To address this issue, we used a strain of mice hereafter referred to as $\mathrm{T} / \mathrm{B}$ monoclonal mice, generated by the cross of (a) influenza HA-specific immunoglobulin heavy- and light-chain knockin mice (32); (b) DO11.10 OVA-specific T cell receptor transgenic mice (33); and (c) RAG-1 knockout mice (34), and (d) extensively backcrossed onto BALB/c background. The $\mathrm{T} / \mathrm{B}$ monoclonal mice provide an excellent model system to study the requirement for thymic-derived Tregs during oral tolerance, since these mice carry naive populations of $\mathrm{T}$ and $\mathrm{B}$ lymphocytes, are devoid of Tregs, and develop exacerbated Th2/IgE responses and lung inflammation after i.p. immunization and respiratory challenge with the cognate antigen OVA-HA (32). The protocol to induce and test oral tolerance and the various experimental groups is indicated in Figure 1A. In brief, $\mathrm{T} / \mathrm{B}$ monoclonal mice were
A

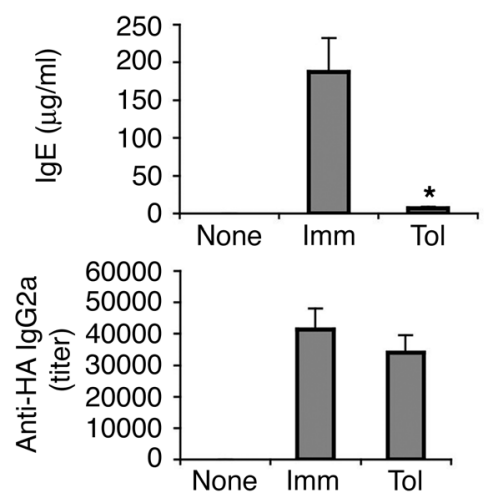

Serum

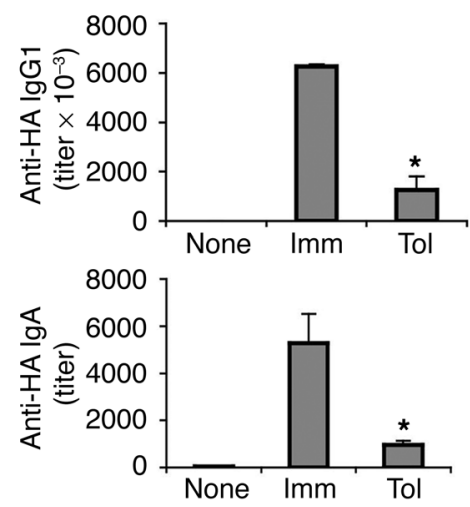

B

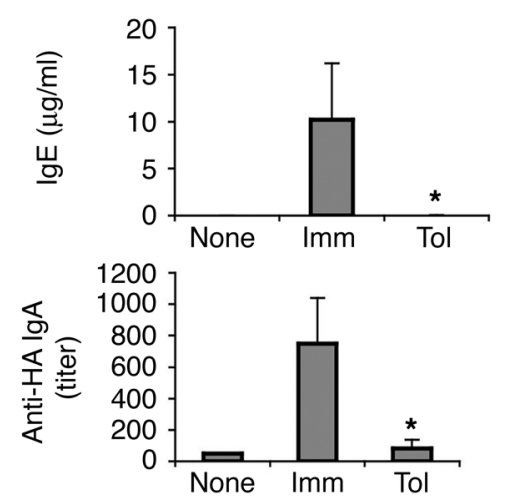

Figure 2

Suppression of IgG1 and IgE production by oral tolerance. Imm and Tol experimental groups $(n=5)$ were prepared as described in Figure 1 . Antibody titers in sera $(\mathbf{A})$ and BAL cells $(\mathbf{B})$ were determined by ELISA. Results are expressed as mean \pm SEM. *Significant differences between the Tol and Imm groups $(P<0.05)$ were found for the values of $\lg \mathrm{G} 1$, $\lg \mathrm{E}$, and $\lg A$. 
A

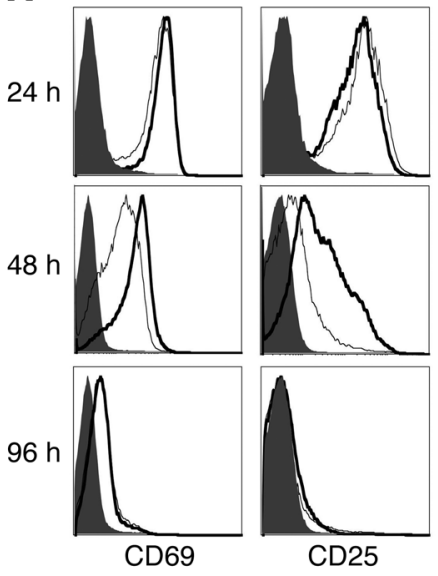

B

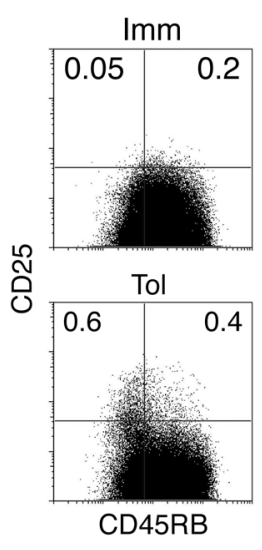

Figure 3

OVA feeding affects early activation of OVA-specific T lymphocytes after i.p. immunization. (A) Imm and Tol groups of mice were prepared as schematized in Figure 1A. Three mice from each group were sacrificed on days 1, 2, and 4 after i.p. immunization (for a total of 9 mice) with OVA-HA, and spleen cells were harvested. Cells were stained with anti-CD4 APC, anti-CD25 PE, and anti-CD69 FITC antibodies and analyzed by FACS. The figure shows representative histograms of cells from Imm (thick lines) and Tol (thin lines) mice. Solid histograms correspond to nonimmunized T/B monoclonal mice. Data are representative of 3 experiments. (B) FACS dot plots of CD4 spleen cells harvested 2 days after i.p. immunization. The same cell suspensions as in $\mathbf{A}$ were stained with anti-CD4 FITC, anti-CD25 APC, and anti-CD45RB PE antibodies. Representative plots of $C D 4^{+}$gated cells are shown. administered OVA in drinking water for 5 days and immunized i.p. 2 days later with OVA-HA in alum. To elicit an asthma-like inflammatory response, mice were administered OVA-HA i.n. on days 14 and 21 after i.p. immunization $(35,36)$. Analysis of lung inflammation was performed 1 day after the second respiratory challenge.

The quantity and composition of the cellular exudate in the airways were determined through the harvesting and analysis of cells in the bronchoalveolar lavage (BAL). Inflammation in the lung parenchyma and goblet cell activation was determined by $\mathrm{H} \& \mathrm{E}$ and PAS staining of lung sections. Figure 1, B and C, shows the analysis of airway inflammation in immunized mice that did or did not receive OVA in drinking water. Those that received OVA in the drinking water prior to OVA-HA i.p. immunization and i.n. administration were referred to as the tolerant group (Tol), and those that received only the latter 2 treatments were referred to as the immune group (Imm) (Figure 1A). Immunization and respiratory challenge of $\mathrm{T} / \mathrm{B}$ monoclonal mice with OVA-HA elicited intense infiltration of eosinophils, neutrophils, and lymphocytes in the airways, cel-

\section{Figure 4}

Effect of previous OVA-feeding on Treg and effector/memory T cell development. The expression of CD25 and CD45RB by OVA-specific $T$ cells from the Tol (OVA fed + OVA-HA immunized), Imm (OVA-HA immunized), and Oral (OVA-fed) groups (as defined in Figure 1A) were analyzed after immunization. $\mathrm{mLN}$ cells were stained with antibodies to CD25, CD45RB, and CD4 and analyzed by FACS. (A) Representative dot plots of gated $\mathrm{CD}^{+}$cells from the Tol and Imm groups at day 22. Similar staining and quadrant gating was used to determine the percentage of CD25-CD45RB low (effector/memory T cells) and CD25 ${ }^{+}$CD45RB low (Treg phenotype) cells in the experimental groups at various times after immunization (see B). (B) Kinetics of appearance of CD25-CD45RB low (effector/memory T cells) and CD25+CD45RB ${ }^{\text {low }}$ (Treg) cells. On day 0 , before immunization, and days 4 and 10 after immunization, $\mathrm{mLN}$ cells from Tol (squares), Imm (diamonds), and Oral (triangles) groups were analyzed for the presence of CD4 cells with effector/memory T cell or Treg phenotypes as described above. Results are expressed as mean \pm SD of 5-15 mice per group per time point. (C) Increased percentage of $C D 25^{+}$CD 45RB low in BAL CD4 cells from Tol mice. BAL was collected from mice of the Tol and Imm groups on day 22. BAL cells were stained with antibodies to CD4, CD25, and CD45RB. The plots show gated CD4+ cells from representative samples. The numbers in the upper right of the plots indicate quadrant percentages. CD25+/CD25- indicates the ratio between CD25+CD45RB low and CD25-CD45RB low cells in each sample. lular inflammation of the lung parenchyma, and production of mucus by goblet cells (Figure 1, B and C; Imm group). In contrast, mice pretreated with OVA in the drinking water displayed muchreduced airway inflammation (Figure 1, B and C; Tol group). In particular, eosinophil numbers in BAL were reduced by more than 10 -fold. Oral antigen administration also prevented goblet cell activation and inflammation of lung parenchyma (Figure 1C; compare the stained sections from Imm and Tol mice).

Oral administration of OVA suppresses byper-IgE and -IgG1 responses. Tol group mice displayed a robust inhibition of both hyper-IgE and -IgG1 antibody production, as demonstrated by the reduced

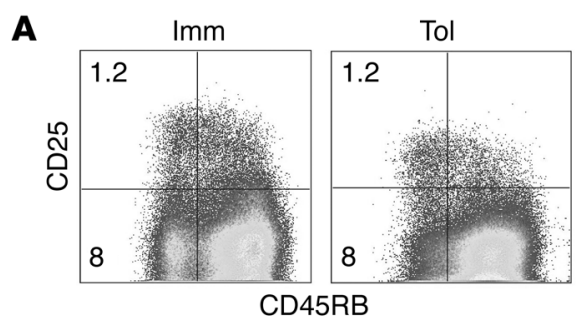

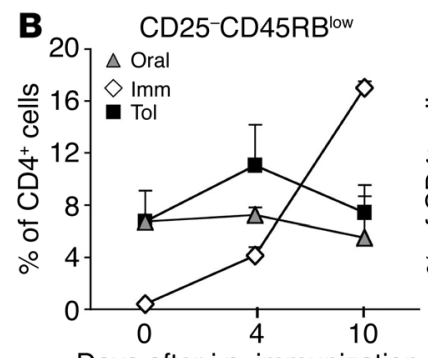

Days after i.p. immunization

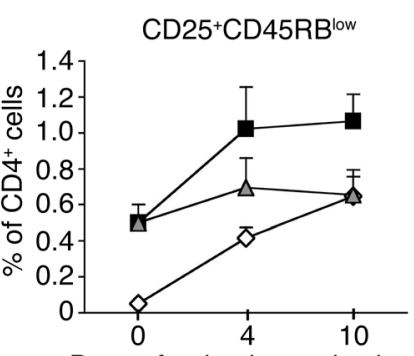

Days after i.p. immunization
C

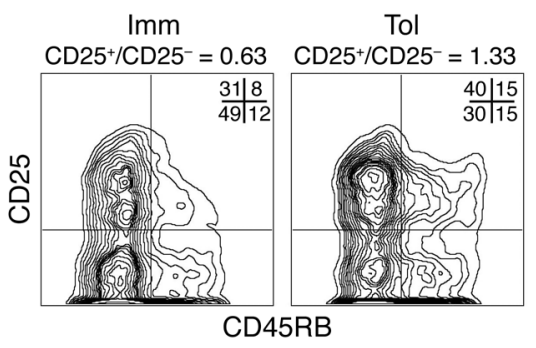



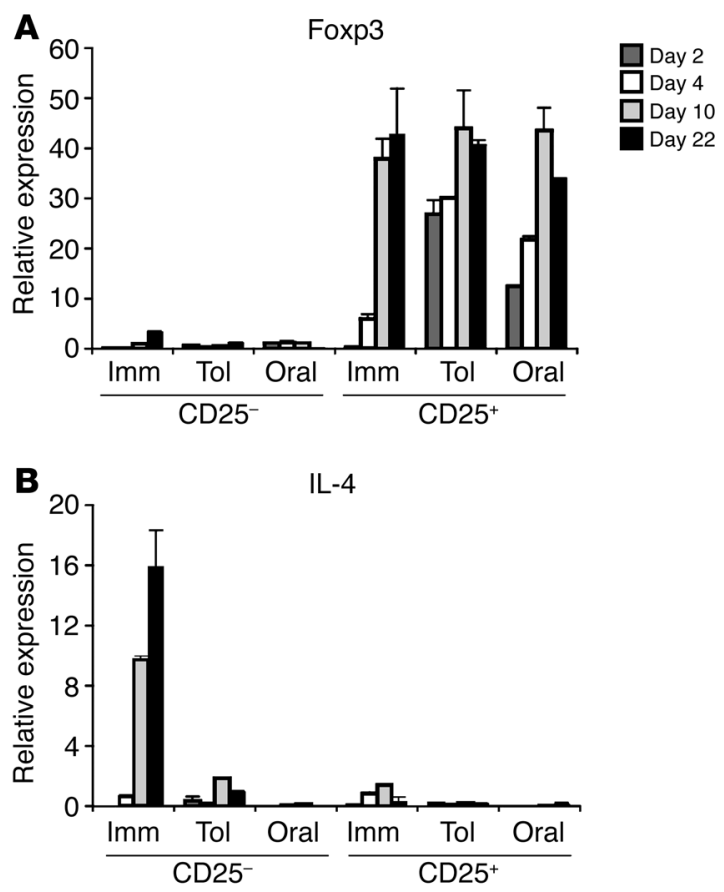

levels of these 2 isotypes in serum (Figure 2A) and BAL (Figure 2B) compared with those in the Imm group. IgA, although described as an isotype induced by oral tolerance (2), was also lower in tolerant mice. Since the $\mathrm{B}$ cells in the $\mathrm{T} / \mathrm{B}$ monoclonal mice do not recognize OVA and the HA peptide was not included in the oral treatment, it is understandable that IgA antibodies were not induced during OVA feeding. Production of IgG2a antibodies did not differ between the Tol and Imm groups. IgG2a antibody levels after i.p. immunization were about 100-fold lower than IgG1 levels, as the response of the $\mathrm{T} / \mathrm{B}$ monoclonal mice is dominated by $\mathrm{Th} 2$-dependent isotypes (32). Analysis of spleen and mesenteric lymph node ( $\mathrm{mLN}$ ) cells on days 10 and 22 after i.p. immunization demonstrated that the oral administration of OVA prevented Th2 differentiation (measured by IL-4 production; Supplemental Figure 1; supplemental material available online with this article; doi:10.1172/JCI24487DS1), formation of GCs (Supplemental Figure 1, B and C), and immunoglobulin class switching (Supplemental Figure 1B). Altogether, these results demonstrate that oral tolerance to a Th2 response can be efficiently induced in the absence of naturally occurring Tregs.

In the experiments described above, oral antigen administration preceded i.p. immunization. In order to determine whether this sequence of treatments was necessary for effective induction of tolerance, we performed experiments in which oral OVA administration was started on the same day as i.p. OVA-HA immunization. No tolerance was observed with this protocol, as demonstrated by analysis of lung inflammation, BAL cellular content, and IgE production (Supplemental Figure 2).

Oral OVA administration affects the activation of OVA-specific T lymphocytes afteri.p. immunization. Immunization of T/B monoclonal mice with i.p. OVA-HA leads to the activation and differentiation of OVA-specific $T$ cells $(22,32)$. The early phase of the $T$ cell response lasts about 4 days and is characterized by the swift upregulation of CD25 and CD69 expression and IL-2 secretion, followed by proliferation and, finally, contraction of the $T$ cell population. The late phase takes place mostly during the second week after immuni-

\section{Figure 5}

Differential kinetics of appearance of Foxp $3^{+}$or IL-4+ $\mathrm{T}$ cells through oral feeding and i.p. immunization. The expression of Foxp3 (A) and IL-4 (B) mRNA by purified OVA-specific CD25+ and CD25- T cells from Tol, Imm, and Oral groups was analyzed on several days after immunization. For all groups, days were numbered as in Figure $1 \mathrm{~A}$. $\mathrm{CD} 4{ }^{+} \mathrm{CD} 25^{+}$and $\mathrm{CD} 4{ }^{+} \mathrm{CD} 25^{-}$cells were purified from pooled spleen cells and $\mathrm{mLNs}$ of 3 mice per sample by magnetic sorting. Expression of Foxp3 and IL-4 was determined by real-time PCR as described. Results are expressed as mean and STD of 3 wells per sample and are representative of 3 experiments.

zation and is characterized by the appearance of effector Th cells $\left(\mathrm{CD} 45 \mathrm{RB}^{\text {low }} \mathrm{CD} 44^{\text {hi }}\right)$ that secrete IL-4 $(22,32)$. Since we showed that IL-4 production was inhibited in the animals exposed to OVA in the drinking water, we sought to determine whether the early phase of the $\mathrm{T}$ cell response was also affected. Toward that end, we analyzed the kinetics of CD25 and CD69 expression in spleen cells of mice after i.p. immunization. We found that CD25 and CD69 upregulation was similar in the Imm and Tol groups at 24 hours after i.p. immunization (Figure 3A; top panels). However, cells of Tol group mice expressed lower levels of CD69 and CD25 at 48 hours (Figure $3 \mathrm{~A}$; middle panels). Although at 48 hours, overall CD25 levels were lower in the Tol group mice, a population of CD25 hi CD45RB low $T$ cells (the phenotype of Tregs) was increased in this group (Figure 3B). By 96 hours, CD69 and CD25 were downregulated in both the Imm and Tol groups (Figure 3A; bottom panels). These results indicate that previous administration of OVA in the drinking water curtails the early $\mathrm{T}$ cell-activation phase induced by subsequent i.p. immunization with OVA-HA.

CD45RB is expressed at high levels on naive T cells and is downregulated in antigen-experienced cells (37). The CD45RB ${ }^{\text {hi }} \mathrm{CD} 25^{+}$ population represents recently activated cells, whereas the

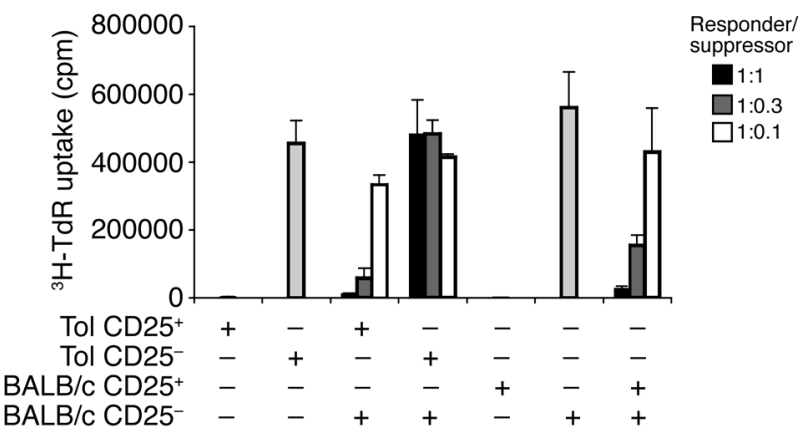

\section{Figure 6}

$\mathrm{CD} 4^{+} \mathrm{CD} 25^{+} \mathrm{T}$ cells induced by oral tolerance are anergic and suppressive in vitro. T/B monoclonal mice were administered OVA in drinking water and immunized with OVA-HA as represented in Figure 1A. Ten days after immunization, spleen and $\mathrm{mLN}$ cells were collected and pooled for the sorting of $\mathrm{CD} 4{ }^{+} \mathrm{CD} 25^{+}$and $\mathrm{CD} 4{ }^{+} \mathrm{CD} 25^{-}$populations. Purified $\mathrm{CD} 4{ }^{+} \mathrm{CD} 25^{-}$and $\mathrm{CD} 4{ }^{+} \mathrm{CD} 25^{+}$cells from Tol T/B monoclonal mice (Tol) or from BALB/c mice were stimulated in vitro with anti-CD3 antibodies and APCs $\left(2 \times 10^{4} \mathrm{CD} 4\right.$ cells $+4 \times 10^{4} \mathrm{APC}$ cells/well). For coculture experiments, $2 \times 10^{4} \mathrm{CD} 4^{+} \mathrm{CD} 25^{-} \mathrm{BALB} / \mathrm{c}$ cells (responder cells) were stimulated with anti-CD3 antibodies and APCs in the presence of putative suppressor cells from Tol or BALB/c mice at responder/suppressor ratios of 1.0:1.0, 1.0:0.3, and 1.0:0.1. Proliferation was determined by ${ }^{3} \mathrm{H}$-thymidine $\left({ }^{3} \mathrm{H}-\mathrm{TdR}\right)$ incorporation. Results are expressed as mean \pm SD of triplicate wells. 


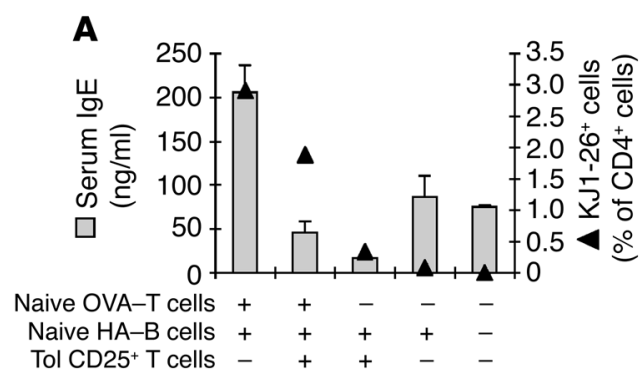

B

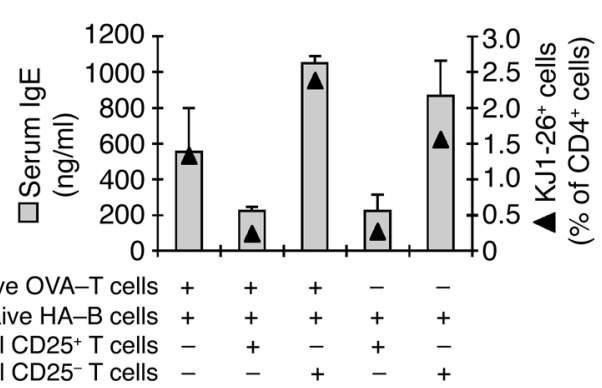

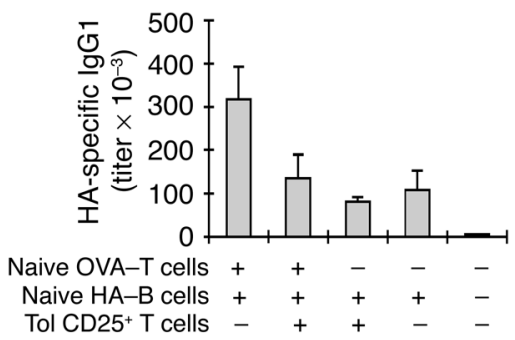

C

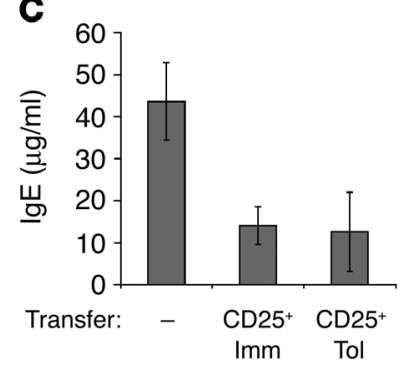

\section{Figure 7}

$\mathrm{CD} 4{ }^{+} \mathrm{CD} 25^{+} \mathrm{T}$ cells induced by oral tolerance or immunization suppress IgE production in vivo. T/B monoclonal mice were administered OVA in drinking water and immunized with OVA-HA as represented in Figure 1A. Ten days after immunization, spleen and $\mathrm{mLN}$ cells were collected and pooled for the sorting of $\mathrm{CD}^{+}{ }^{+} \mathrm{CD} 25^{+}$and $\mathrm{CD} 4{ }^{+} \mathrm{CD} 25^{-}$populations. (A and B) $5 \times 10^{5} \mathrm{CD} 4^{+} \mathrm{CD} 25^{+}$or $\mathrm{CD} 4^{+} \mathrm{CD} 25^{-}$ from Tol T/B monoclonal mice cells were injected i.v. into BALB/c mice together with $5 \times 10^{5} \mathrm{OVA}$-specific naive $\mathrm{CD} 4^{+}$cells and $1 \times 10^{7} \mathrm{HA}$-specific naive $\mathrm{B}$ cells. One day after transfer, recipient mice were immunized i.p. with OVA-HA in alum. The figure shows total IgE and HA-specific IgG1 serum levels (bars) as well as the percentage of donor OVA-specific KJ1-26+ cells (triangles) 14 days after immunization. Results are expressed as mean \pm SEM of 3-4 mice per group. Results in $\mathbf{A}$ and $\mathbf{B}$ correspond to 2 independent experiments. (C) $\mathrm{CD} 4{ }^{+} \mathrm{CD} 25^{+}$cells were purified from Tol and Imm groups 10 days after i.p. immunization and transferred to T/B monoclonal mice $\left(5 \times 10^{5}\right.$ cells/mouse). One day later, mice were immunized i.p. with OVA-HA in alum. The graphic shows serum IgE levels on day 15 after immunization. Results are expressed as mean \pm SEM of 3 mice per group.
CD25-CD45RB ${ }^{\text {low }}$ populations over time was most marked in the Imm group whereas the increase in the proportion of $\mathrm{CD} 25^{+} \mathrm{CD} 45 \mathrm{RB}^{\text {low }}$ cells was more or less parallel in the Tol and Imm groups (Figure 4B). Similar results were obtained with spleen samples (Supplemental Figure 3, A and B). When we analyzed the BAL cells after respiratory challenge, we found that the Tol group had more $\mathrm{CD} 25^{+} \mathrm{CD} 45 \mathrm{RB}^{\text {low }}$ cells than CD25-CD45RB ${ }^{\text {low }}$ cells while the converse was true for the mice of the Imm group (Figure 4C).

The above results show that CD $25^{+}$CD 45 RB $^{\text {low }}$ cells, which have the surface phenotype of Tregs, develop in all mice exposed to oral OVA, i.p. OVA-HA, or both. By the time of i.p. immunization, $\mathrm{CD} 25^{+} \mathrm{CD} 45 \mathrm{RB}^{\text {low }}$ cells were already present in mice that had received oral OVA, and their numbers further increased with immunization. The population of CD25CD45RB ${ }^{\text {low }}$ cells also developed in all mouse groups exposed to OVA, but it became proportionally larger only in mice of the Imm group, in which the first antigen exposure was by the i.p. route. Thus, oral immunization, compared with i.p. immunization, favors the induction of $\mathrm{CD} 25^{+} \mathrm{CD} 45 \mathrm{RB}^{\text {low }}$ cells over the induction of CD25CD45RB low cells.

Oral tolerance induces Foxp $3^{+} \mathrm{CD} 25^{+}$ Tregs. To determine whether the $\mathrm{CD} 25^{+} \mathrm{CD} 45 \mathrm{RB}^{\text {low }}$ cells induced in the $\mathrm{CD} 45 \mathrm{RB}^{\text {low }}$ is a heterogeneous population containing differentiated effector/memory $\mathrm{T}$ cells (contained in the CD45RB ${ }^{\text {low }} \mathrm{CD} 25^{-}$ population) and Treg cells (the $\mathrm{CD} 45 \mathrm{RB}^{\text {low }} \mathrm{CD} 25^{+}$population) $(38-40)$. To determine how oral tolerance affects the differentiation of $\mathrm{T}$ cells into cells with effector/memory phenotype and Tregs, we quantified CD45RB ${ }^{\text {low }} \mathrm{CD} 25^{-}$and $\mathrm{CD} 45 \mathrm{RB}^{\text {low }} \mathrm{CD} 25^{+}$in mLN, spleen, and BAL cells of the Oral (mice fed OVA in drinking water; see Figure 1A), Imm, and Tol groups at several time points after immunization. Figure 4A shows FACS plots of CD25 and CD45RB expression in gated $\mathrm{CD} 4{ }^{+} \mathrm{KJ} 1-26^{+}$cells from the $\mathrm{mLNs}$ of animals pre-exposed or not pre-exposed to OVA in the drinking water, 22 days after i.p. immunization. The Tol and Imm groups displayed comparable frequencies of $\mathrm{CD} 25^{+} \mathrm{CD} 45 \mathrm{RB}^{\text {low }} \mathrm{T}$ cells, but the Imm group reproducibly had a higher percentage of effector/ memory T cells (Figure 4A). The same stainings and quadrants shown in Figure 4A were utilized for the kinetic studies shown in Figure 4B. Analysis of mLNs at day 0 (prior to i.p. immunization) showed that OVA-fed animals (Oral group and Tol group) already had an increased proportion of both CD25-CD45RB low and $\mathrm{CD} 25^{+} \mathrm{CD} 45 \mathrm{RB}^{\text {low }} \mathrm{T}$ cells, reflecting prior exposure to antigen. At later time points, the proportion of $\mathrm{CD} 25^{+} \mathrm{CD} 45 \mathrm{RB}{ }^{\text {low }}$ $\mathrm{T}$ cells increased in the Tol group, which received i.p. immunization, unlike the Oral group. The increase in the proportion of
T/B monoclonal mice exposed to oral OVA and/or i.p. OVA-HA were bona fide Tregs, we studied the expression of Treg-associated genes Foxp 3 and CTLA- 4 in purified $\mathrm{CD} 4^{+} \mathrm{CD} 25^{+}$and $\mathrm{CD} 4^{+} \mathrm{CD} 25^{-}$cells. Unlike other Treg markers, Foxp3 expression has been reported as not being upregulated in conventional mouse $T$ cells upon their activation (41-43). Thus, Foxp3 expression is the marker that best correlates with Treg function. We also analyzed the expression of cytokines associated with suppressor (IL-10, TGF- $\beta$ ) or effector (IL-4, IL-5, and IFN- $\gamma$ ) activity.

$\mathrm{CD} 4^{+} \mathrm{CD} 25^{-}$and $\mathrm{CD} 4^{+} \mathrm{CD} 25^{+}$cells were purified by magnetic sorting from pooled spleen and $\mathrm{mLN}$ cells at several time points after i.p. immunization, and mRNA expression in the samples was determined by quantitative real-time PCR. Two days after i.p. immunization, Foxp 3 expression by the $\mathrm{CD} 4{ }^{+} \mathrm{CD} 25^{+} \mathrm{T}$ cells in the Tol group was approximately 100 times higher than in the Imm group (Figure 5A). On day 4, the levels of Foxp3 expression in $\mathrm{CD}^{+} \mathrm{CD} 25^{+} \mathrm{T}$ cells from Tol mice were 5-6 times higher than in those from the Imm group. Foxp3 expression was also detected in $\mathrm{CD} 4^{+} \mathrm{CD} 25^{+} \mathrm{T}$ cells from mice that received OVA orally but were not immunized i.p. (Figure 5A; Oral group: days 0, 4, 10, and 22). In the 3 experimental groups, Foxp 3 levels in the $\mathrm{CD} 4^{+} \mathrm{CD} 25^{+}$ samples were similar on days 10 and 22 . Foxp3 expression was virtually undetected in $\mathrm{CD}^{+} \mathrm{CD} 25^{-} \mathrm{T}$ cells from any group at any 
A

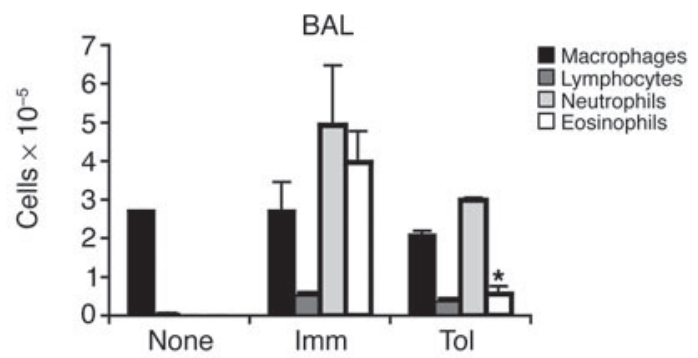

B

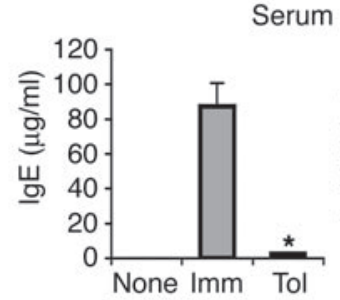

antibodies
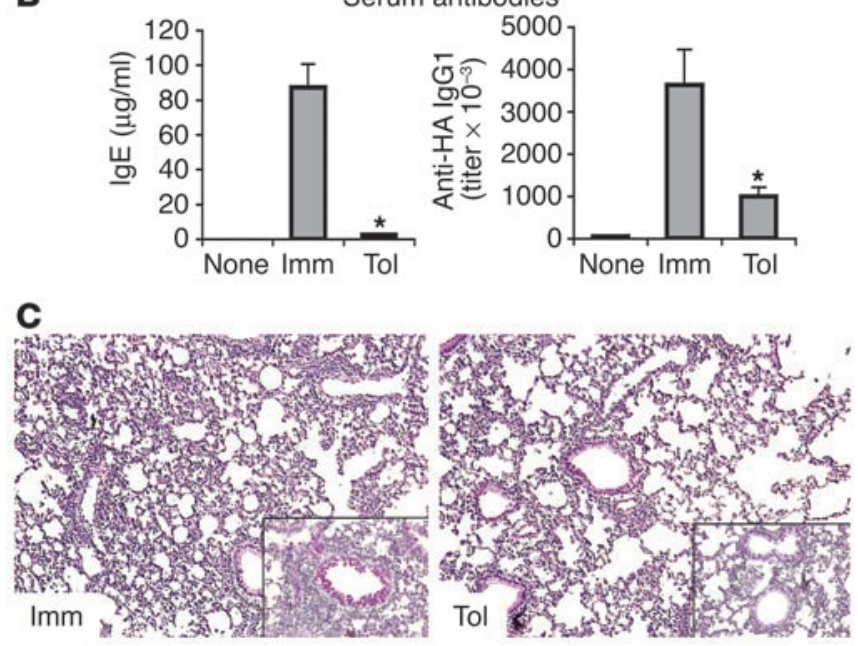

time point. CTLA- 4 expression in the $\mathrm{CD} 25^{+}$population paralleled Foxp3 expression (Supplemental Figure 4A). High IL-4 and IL-5 production were only detected in the $\mathrm{CD} 25^{-}$population of the Imm group (Figure 5B and Supplemental Figure 4F). The expression of IL-10 and IFN- $\gamma$ was relatively low in all groups (Supplemental Figure 4, B and C). We did not detect consistent differences in the levels of expression of TGF- $\beta$ or SMAD2 by purified populations of $\mathrm{CD} 4^{+} \mathrm{CD} 25^{-}$or $\mathrm{CD} 4^{+} \mathrm{CD} 25^{+}$cells from any group (Supplemental Figure 4, D and E).

In sum, Foxp 3 expression was observed in the $\mathrm{CD} 4^{+} \mathrm{CD} 25^{+} \mathrm{T}$ cells from all experimental groups exposed to OVA, either orally, i.p., or both. The main difference found among the groups was in the high expression of the Th2 cytokines IL-4 and IL-5 in the Imm group; expression of these cytokines was undetectable in mice that had previously received oral OVA (Oral and Tol groups). Thus, oral administration of antigen induces OVA-specific naive $T$ cell differentiation to Tregs but not to Th2 effector cells. In contrast, i.p. immunization induces both Th2 and Tregs. In this case, the fact that Tregs develop at the same time as Th2 cells and not before may explain the inability of the Tregs to suppress Th2 differentiation and the asthmatic response.

Tregs generated in $T / B$ monoclonal mice suppress in vitro proliferation and in vivo IgE responses. We next assessed the suppressor activity of oral tolerance-induced antigen-specific $\mathrm{CD} 4^{+} \mathrm{CD} 25^{+} \mathrm{T}$ cells using a standard in vitro assay. $\mathrm{CD} 4^{+} \mathrm{CD} 25^{+}$and $\mathrm{CD} 4^{+} \mathrm{CD} 25^{-} \mathrm{T}$ cells were purified from spleen and mLN cells from Tol group mice on day 10 after i.p. immunization. These cells were tested for their ability to proliferate upon anti-CD3 antibody stimulation and to suppress the proliferation of purified $\mathrm{CD}^{+} \mathrm{CD} 25^{-}$cells from wild-type $\mathrm{BALB} / \mathrm{c}$ mice. As shown in Figure 6, $\mathrm{CD} 4^{+} \mathrm{CD} 25^{+} \mathrm{T}$ cells from Tol-group mice were as anergic and suppressive as freshly isolated $\mathrm{CD} 4^{+} \mathrm{CD} 25^{+}$

\section{Figure 8}

$\mathrm{IL}-10$ is not required to establish oral tolerance in T/B monoclonal mice. T/B monoclonal IL-10-/- mice were administered OVA orally, immunized i.p. with OVA-HA, and challenged i.n. with OVA-HA as schematized in Figure $1 \mathrm{~A}$. The experimental groups were named as described in Figure 1A. The results shown are representative of 3 experiments. (A) BAL cells were collected 24 hours after the second i.n. challenge (day 22) and were analyzed by differential staining. Results are expressed as mean \pm SEM of 3 mice per group. *Significant differences were found between eosinophil numbers in BAL cells of Imm and Tol groups $(P<0.05)$. (B) The levels of $\operatorname{IgE}$ and $\operatorname{IgG} 1$ were analyzed in serum samples from day 22. Results are expressed as mean \pm SEM of 3 mice per group. *Significant differences were found between values of $\mathrm{Imm}$ and Tol groups $(P<0.05)$. (C) Representative lung sections from mice on day 22 of immunization. The large pictures show H\&E staining, and the insets show PAS/hematoxylin staining. Note the peribronchovascular inflammatory cell infiltration (large picture) and the mucus ${ }^{+}$PAS $^{+}$ bronchi (inset) in the Imm sample (left panels). Tol mice showed much reduced inflammation and mucus (right panels).

T cells from wild-type BALB/c mice whereas $\mathrm{CD} 4^{+} \mathrm{CD} 25^{-} \mathrm{T}$ cells from Tol-group mice exhibited high proliferation in response to anti-CD3 stimulation and no suppressor activity.

We also tested to determine whether the transfer of OVA-specific $\mathrm{CD} 4^{+} \mathrm{CD} 25^{+}$cells from Tol-group mice could suppress in vivo the IgE response to OVA-HA. CD $4^{+} \mathrm{CD} 25^{+}$and $\mathrm{CD} 4^{+} \mathrm{CD} 25^{-}$ $\mathrm{T}$ cells were purified from Tol-group mice on day 10 after i.p. immunization. These purified cells were transferred into BALB/c mice with or without naive anti-OVA $\mathrm{T}$ cells and/or naive antiHA B cells, and recipient mice were immunized 1 day after. On day 14 after immunization, the production of $\operatorname{IgG} 1$ and $\operatorname{IgE}$ as well as the expansion of OVA-specific $T$ cells were determined. The 2 experiments indicated in Figure 7, A and B, showed that OVA-specific $\mathrm{CD} 4{ }^{+} \mathrm{CD} 25^{+}$cells from Tol-group mice diminished $\operatorname{IgE}$ production and overall expansion of OVA-specific $\mathrm{T}$ cells (identified by staining with the anti-clonotypic antibody KJ1-26). In contrast, OVA-specific CD25- cells from the Tol group did not suppress naive cell responses; furthermore, these cells were able to proliferate and provide help for IgE production at levels comparable to those seen in naive OVA-specific T cells (Figure 7B). These results confirm that OVA-specific Tregs generated in $\mathrm{T} / \mathrm{B}$ monoclonal mice after oral exposure and immunization are suppressive in vivo and in vitro. Moreover, the results show that IgE responses can be attained (and regulated) in a transfer system into $\mathrm{BALB} / \mathrm{c}$ mice in a way that is qualitatively similar to $\mathrm{T} / \mathrm{B}$ monoclonal mice, although displaying lower overall $\operatorname{IgE}$ values.

We also investigated whether cells with Treg phenotypes induced after i.p. immunization could suppress the Th2/IgE response. We purified $\mathrm{CD} 25^{+}$cells from $\mathrm{T} / \mathrm{B}$ monoclonal mice that had either been immunized i.p. with OVA-HA (Imm group) or had received OVA orally and subsequently been immunized i.p. with OVA-HA (Tol group). In both groups cell purification was performed 10 days after i.p. immunization. A total of $5 \times 10^{5}$ $\mathrm{CD} 4^{+} \mathrm{CD} 25^{+} \mathrm{T}$ cells were transferred to naive $\mathrm{T} / \mathrm{B}$ monoclonal mice, and the mice were immunized i.p. 1 day later with OVA-HA in alum. As shown in Figure 7C, cells from both the Imm- and the Tol-group mice efficiently suppressed the IgE response. Thus, both oral administration of antigen and i.p. immunization with adjuvant induce functional Tregs, but in the latter case, Treg development does not occur sufficiently early to affect the course of the concomitant Th2 response. 


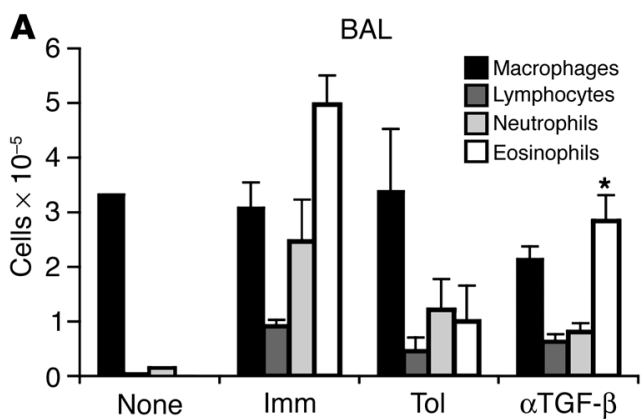

B

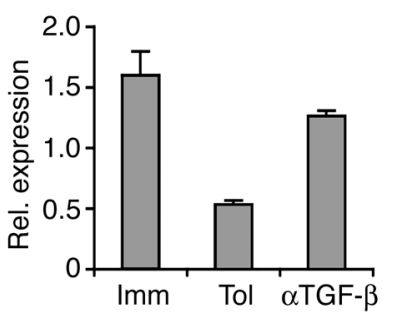

BAL IL-4
C

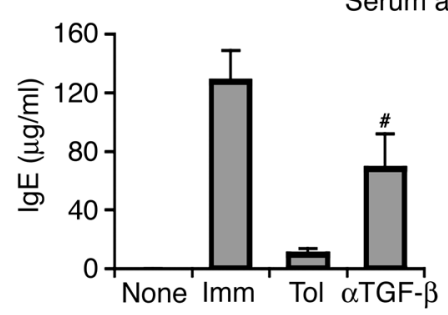

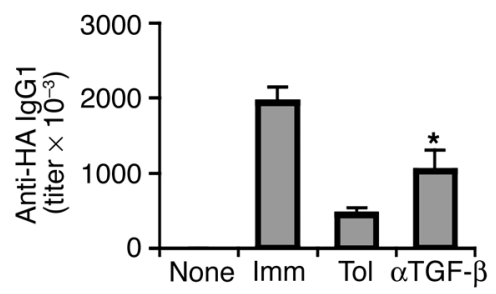

Figure 9

TGF- $\beta$ is necessary for establishing oral tolerance in the absence of thymus-derived Tregs. Anti-TGF- $\beta$ antibody (1D11) was administered to T/B monoclonal mice before, during, and immediately after oral OVA treatment (days $-8,-5,-2$, and 1 according to the schematic of Figure 1A). The mice were then immunized i.p. with OVA-HA and challenged i.n. as described in Figure 1A. None, Imm, and Tol groups were treated as described in Figure 1A. Analyses were performed on day 22 after i.p. immunization. The results shown are representative of 3 independent experiments. (A) BAL cellular infiltrate. Note that the anti-TGF- $\beta$ ( $\alpha$ TGF- $\beta$ ) treatment reversed the suppression of eosiniphilic inflammation. (B) Increased IL-4 expression in BAL cells from anti-TGF- $\beta$-treated group. The expression of IL-4 in total BAL cells was determined by real-time PCR. Results are expressed as mean \pm SD of 3 wells per sample. (C) The levels of total IgE and HA-specific lgG1 in sera were determined by ELISA. Results are expressed as mean \pm SEM of 5 mice per group. *Significant differences $(P<0.05)$ between values of anti-TGF- $\beta$-treated and Tol groups; ${ }^{\#} P=0.07$ between anti-TGF- $\beta$-treated and Tol groups.

IL-10 is not necessary for the induction of oral tolerance in $T / B$ monoclonal mice. The mechanism of suppression by naturally occurring Tregs in vitro is cell-contact dependent and cytokine independent whereas the cytokines IL-10 and TGF- $\beta$ have been shown to be important for in vivo suppression in several experimental models (44-46). In addition, both IL-10 and TGF- $\beta$ were found to have the ability to induce Treg activity in vitro. While TGF- $\beta$ has been implicated in oral tolerance, the role of IL-10 in oral tolerance is controversial $(4,47,48)$. We next investigated to determine whether IL-10 and TGF- $\beta$ are required for induction of oral tolerance in the absence of thymus-derived Tregs.

IL-10-deficient T/B monoclonal mice were generated by crossing $\mathrm{T} / \mathrm{B}$ monoclonal mice with $\mathrm{BALB} / \mathrm{c} \mathrm{IL}-10^{-/-}$mice. As shown in Figure 8, IL-10-/- T/B monoclonal mice developed hyper-IgE response and airway inflammation after i.p. immunization and respiratory challenge. However, when compared to that in IL- $10^{+}$ $\mathrm{T} / \mathrm{B}$ monoclonal mice (Figures 1 and 2), serum IgE and eosinophilia in IL-10-/- T/B monoclonal mice were modestly but reproducibly reduced. Oral OVA administration before i.p. immunization resulted in suppression of all asthma parameters analyzed, namely BAL eosinophilic infiltrate, lung inflammation, and mucus secretion (Figure 8, A and C). Interestingly, neutrophilic infiltration was not reduced in Tol group IL-10-/- T/B monoclonal mice, probably because lung neutrophilic infiltration is mediated by Th1 cells (49-51). From the early days of IL-10 research, it has been known that IL-12 and IFN- $\gamma$, 2 critical cytokines in Th1 biology, are targets of IL-10 inhibition (52). Thus, it is not surprising that this particular aspect of lung inflammation is not significantly reduced in Tol group $\mathrm{T} / \mathrm{B}$ monoclonal IL-10-deficient mice.

IL-10-/- T/B monoclonal mice of the Tol group displayed strong inhibition of $\mathrm{B}$ cell responses, such as the production of IgG1 and IgE (Figure 8B) and GC reaction (Supplemental Figure 5A). Like tolerance induction in IL-10+ $\mathrm{T} / \mathrm{B}$ monoclonal mice, that in IL-10-/- mice was accompanied by a lower accumulation of CD 45RB ${ }^{\text {low }} \mathrm{CD} 25$ - (effector/ memory $\mathrm{T}$ cells) cells (Supplemental Figure 5B). IL-10-/- T/B monoclonal mice were also susceptible to nasal tolerance (Supplemental Figure 6). Thus, in this experimental system, IL-10 is not necessary either for the development of the asthmatic response or for the establishment of effective mucosal tolerance.

$T G F-\beta$ is required for oral tolerance in $T / B$ monoclonal mice. We tested next to determine whether TGF- $\beta$ was required during the initial oral tolerization phase. To this end, we injected $\mathrm{T} / \mathrm{B}$ monoclonal mice with the depleting anti-TGF- $\beta$ antibody 1D11 before, during, and immediately after oral OVA administration. As shown in Figure 9, neutralization of TGF- $\beta$ impaired oral tolerization, reverting suppression of eosinophilic airway inflammation, production of IL-4 by cells in BAL, and production of seric IgG1 and IgE (Figure 9, $\mathrm{A}-\mathrm{C})$. We also observed a reversion of the suppression of GC formation (Supplemental Figure 7A) and of the development of $\mathrm{CD} 45 \mathrm{RB}^{\text {low }} \mathrm{CD} 25^{-}$ $\mathrm{T}$ cells (Supplemental Figure 7B).

To determine the role of TGF- $\beta$ in the in vivo differentiation of Tregs during OVA feeding, we administered anti-TGF- $\beta$ antibody 1 day before and 2 days after the beginning of oral treatment. On day 5 of oral treatment (Figure 1A; day -2), we analyzed the expression of CD25 and CD45RB in mLN cells. We observed an increase in $\mathrm{CD}^{2} 5 \mathrm{RB}^{\text {low }} \mathrm{CD} 25^{+}$cells (as well as in recently activated $\mathrm{CD} 45 \mathrm{RB}^{\text {hi }} \mathrm{CD} 25^{+}$cells) in mice that received OVA orally compared with untreated $\mathrm{T} / \mathrm{B}$ monoclonal mice (Figure 10A). The same analysis enabled us to confirm that, as expected, unimmunized $\mathrm{T} / \mathrm{B}$ monoclonal mice have no $\mathrm{CD} 45 \mathrm{RB}^{\text {low }} \mathrm{CD} 25^{+}$cells, the region in the FACS plot in which Tregs are found (Figure 10A). AntiTGF- $\beta$ treatment resulted in only a moderate reduction of the $\mathrm{CD} 45 \mathrm{RB}^{\text {low }} \mathrm{CD} 25^{+}$population (Figure 10A). In order to determine Foxp3 expression levels, we FACS-sorted the 4 populations defined by anti-CD45RB and anti-CD25 antibodies from mLNs and prepared cDNA for real-time PCR analysis. As anticipated, only CD $45 \mathrm{RB}^{\text {low }} \mathrm{CD} 25^{+}$cells expressed Foxp3. Importantly, anti-TGF- $\beta$ treatment resulted in a 2- to 3-fold reduction of Foxp3 expression in mLN cells (Figure 10B). The reduction in Foxp3 expression was even more marked in spleen cells (Supplemental Figure 8).

Our results are consistent with the notion that oral antigen administration induces antigen-specific Tregs in a process that requires TGF- $\beta$ for full Foxp3 induction. Our results from the 
A
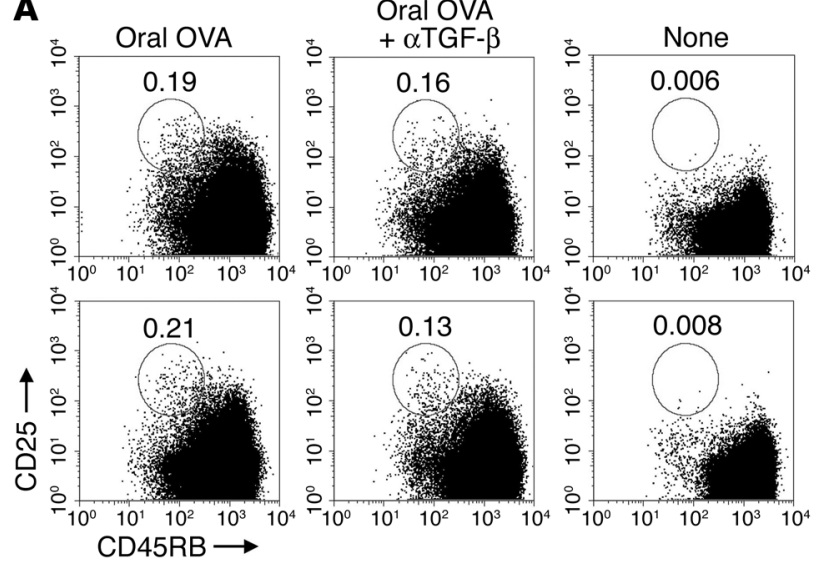

B

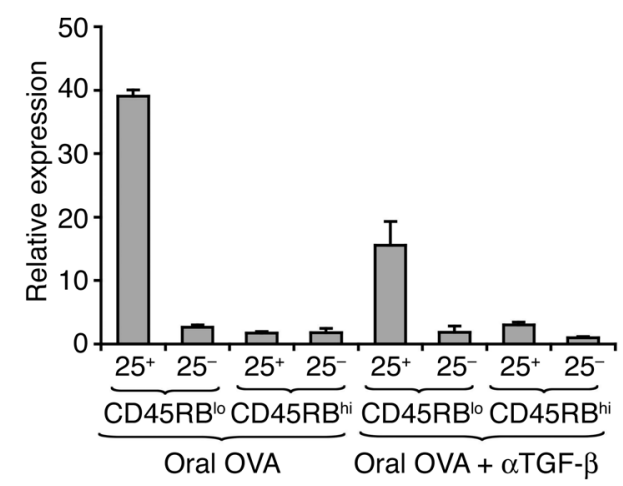

adoptive transfer experiments strongly support the notion that antigen-specific Tregs induced by oral tolerance prevent asthmatype responses by inhibiting Th2 differentiation and class switching to IgE in the lymphoid organs.

\section{Discussion}

In this manuscript, we make 2 main observations. The first is that oral tolerance can be induced in the absence of thymic-derived Tregs. Establishment of oral tolerance correlates with the de novo induction of antigen-specific $\mathrm{CD} 4^{+} \mathrm{CD} 25^{+} \mathrm{Foxp} 3^{+}$Tregs, which is impaired when TGF- $\beta$ is blocked. Second, we show that a single immunization with antigen plus adjuvant leads to the generation of functional antigen-specific Tregs, which, in this case, occurs in parallel with the generation of effector Th2 cells.

Several mechanisms have been proposed to account for oral tolerance, such as clonal deletion of antigen-specific $\mathrm{T}$ cells, immune deviation, $T$ cell anergy, and the induction of Tregs $(4,47,53)$. In fact, the transfer of tolerance by Tregs obtained from animals that have been fed antigen has been known for more than 25 years $(54,55)$. It has been shown, using OVA-specific DO11.10 TCR transgenic mice, that in tolerant mice there is an increase in the $\mathrm{CD} 4{ }^{+} \mathrm{CD} 25^{+}$ population. These $\mathrm{CD} 25^{+}$cells prevented a delayed type hypersensitivity response upon transfer into BALB/c mice (56). Several groups have used adoptive transfer of DO11.10 OVA-TCR transgenic $\mathrm{T}$ cells into wild-type animals to demonstrate the induction of $\mathrm{CD}^{+}$cells that are able to transfer tolerance $(11,14,57)$. Recently, Ostroukhova et al. (17) described Foxp3 expression in antigen-stimulated cultures of membrane TGF- $\beta^{+} \mathrm{CD} 4^{+} \mathrm{T}$ cells from mice tolerized to OVA by respiratory antigen exposure.

\section{Figure 10}

Neutralization of TGF- $\beta$ in vivo inhibits early Foxp3 expression. T/B monoclonal mice were injected with anti-TGF- $\beta 1$ day before and 3 days after the beginning of administration of $1 \%$ OVA in the drinking water. After 5 days of oral-OVA, CD4+ $\mathrm{mLN}$ cells were analyzed for expression of CD45RB and CD25 by FACS and for expression of Foxp3 by real-time PCR. (A) mLN cells from mice that received oral-OVA alone, from mice that received anti-TGF- $\beta$ antibodies and oral-OVA, and from untreated T/B monoclonal mice were stained with antibodies for CD4, CD45RB, and CD25. The figure shows representative plots of $\mathrm{CD}^{+}$gated cells. (B) $\mathrm{CD} 4^{+}$cells from pooled $\mathrm{mLN}$ (4 mice per group) were sorted in a MoFlo flow cytometer into CD45RB low CD4+CD25+, CD45RB low CD4+CD25-, CD45RB ${ }^{\text {hi }} C D 4{ }^{+} C D 25^{+}$, and CD45RB ${ }^{\text {hi }} C D 4{ }^{+}$CD25- fractions. Foxp3 expression in the samples was determined by real-time PCR. Results are expressed as mean \pm SD of triplicate wells.

Stock et al. showed that splenic CD8 ${ }^{+}$DC from mice tolerized to OVA through the airways induced antigen-specific Tregs that expressed Foxp3, Tbet, IFN- $\gamma$, and IL-10 (23). In these and other studies, a direct or inductive role for thymus-derived Tregs in antigen-specific tolerance could not be ruled out.

To clarify in a definitive manner the need for thymus-derived Treg cells in oral tolerance, we studied mucosal tolerance in mice that lack naturally occurring thymus-derived Tregs (Figure 10A) and showed that oral administration of OVA previous to i.p. immunization with OVA-HA dramatically suppressed an asthmatic inflammatory response in these mice.

We also observed that tolerance was associated with the induction of antigen-specific $\mathrm{CD} 4^{+} \mathrm{CD} 25^{+}$cells that expressed markers of naturally occurring Tregs, such as Foxp3 and CTLA-4 (13, $41-43)$. $\mathrm{CD}^{+} \mathrm{CD} 25^{+}$cells induced by oral antigen administration behaved as naturally occurring Tregs, as they were anergic and suppressive upon stimulation with anti-CD3 antibodies in vitro. Importantly, transfer of these cells led to suppression of the $\operatorname{IgE}$ response. Thus, oral delivery of antigen induced antigen-specific naive CD 4 cells to become Tregs by a process that is independent of the presence of thymic-derived Tregs. Although we did not formally exclude the possibility that orally administered OVA makes its way to the thymus and promotes the development of immature cells into Tregs, we believe that this possibility is unlikely given the relatively rapid appearance of $\mathrm{CD} 25^{+} \mathrm{Foxp} 3^{+}$ cells (Figure 10, A and B) and recent reports demonstrating antigen-induced generation of Tregs in thymectomized animals (20) and the conversion of naive mature peripheral CD25-Foxp3$\mathrm{T}$ cells into Tregs in a transfer system (22).

The generation of antigen-specific Tregs by oral administration of antigen explains the discrepancies between our conclusions and those of Dubois and coworkers (16). These authors concluded that naturally occurring Tregs are required for oral tolerance. They antibody-depleted CD25 cells in B6 mice and showed that oral tolerance was abrogated. However, since the last antibody treatment was performed 7 days after the oral feeding, it is likely that the authors depleted not only the naturally occurring Tregs but also those Tregs that had been peripherally generated by the oral feeding.

Recently, Apostolou and von Boehmer showed that continuous subcutaneous antigen delivery induced Foxp $3^{+}$Tregs that were indistinguishable from naturally occurring Tregs (20). Our results extend those of Apostolou and von Boehmer by demonstrating that antigen-specific Tregs can be induced by mucosal delivery of 
antigen. Importantly, we found that a single parenteral immunization in the presence of antigen also induced Treg development. In this case, however, Tregs were induced concomitantly to Th2 cells.

If antigen-specific Tregs can be generated upon single immunization even in the presence of adjuvant, one may wonder why these Treg do not control the primary immune response. In fact, as we previously reported, T/B monoclonal mice develop hyper-Th2 and hyper-IgE responses after a single immunization, indicating lack of regulation. The explanation is provided by our kinetic data (Figures 4, 5, and 10), which show that high Foxp3 expression is attained only 10 days after a single i.p. immunization of $\mathrm{T} / \mathrm{B}$ monoclonal mice. At this time, there is already a robust Th2 response. In order to inhibit Th2 differentiation and hyper-IgE production, regulation has to be in place before day 4 after immunization (Supplemental Figure 9), which is not the case during the normal course of the response in $\mathrm{T} / \mathrm{B}$ monoclonal mice. However, while the Tregs generated by parenteral exposure to antigen in $\mathrm{T} / \mathrm{B}$ monoclonal mice are not able to control the primary immune response, they may help downregulate further responses or reduce the damage caused by chronic antigenic stimulation. Accordingly, we observed that in $\mathrm{T} / \mathrm{B}$ monoclonal mice repeatedly immunized i.p. with OVA-HA, there was an increase in Foxp3 levels and a decrease in IL-4 production by CD25- $\mathrm{T}$ cells (Supplemental Figure 10).

The role of IL-10 in mucosal tolerance is controversial $(13,17$, $18,58,59)$. In the model of hyper-IgE and asthma described here, oral tolerance did not require IL-10, since IL-10-/- T/B monoclonal mice were as susceptible to oral tolerance as their IL-10+ littermates. However, neutrophilic inflammation was not ameliorated by oral tolerance in IL-10/- mice.

The key role of TGF- $\beta$ in oral tolerance was established long ago $(60,61)$. In contrast, experiments with TGF- $\beta 1^{-/-}$mice showed that oral tolerance could be achieved in the absence of TGF- $\beta 1$, although the degree of inhibition of the response by antigen feeding was much lower in TGF- $\beta 1^{-/-}$mice than in TGF- $\beta 1^{+}$control mice (62). This experimental system was further complicated by anti-lymphocyte function-associated antigen-1-antibody (anti-LFA-1-antibody) treatment of the mice. In our experimental model, blockade of TGF- $\beta$ caused an almost complete reversal of the suppression of GC formation and memory T cell development while other parameters, such as eosinophilia and IgE production, were only partially, albeit significantly, reversed. At this time we do not know whether the residual suppression of IgE and eosinophilia was due to incomplete neutralization of TGF- $\beta$ or to the fact that a small fraction of the suppression operates via TGF- $\beta$-independent mechanisms. For instance, the suppression of neutrophil numbers in BAL was not reversed by anti-TGF- $\beta$ antibodies, which is consistent with the fact the suppression of neutrophil migration may be dependent on IL-10.

It is not completely clear whether, in vivo, TGF- $\beta$ is an inductive stimulus for Treg generation, an effector molecule that mediates Treg suppressive function, or both. It has been proposed that oral administration of antigens induces Th 3 cells. The TGF- $\beta$ produced by Th3 cells would be a major effector molecule in the suppression of responses (28). However, the role of TGF- $\beta$ in the induction of Th 3 cells in the mucosa has not been determined. Our results show that blockade of TGF- $\beta$ in vivo abolishes oral tolerance and considerably impairs the induction of $\mathrm{CD} 25^{+} \mathrm{Foxp}^{+}$Tregs. Given the lack of markers that uniquely identify Th3 cells, the relationship between the Foxp $3^{+}$cells that we describe here and Th3 cells has not been determined. However, oral tolerance in our model was not accompanied by enhanced concentration of active TGF- $\beta$ in the airways (data not shown), suggesting that, in this model, TGF- $\beta$ acts as an inductor of Tregs but not as an effector molecule in the suppression of asthma-like symptoms.

It has been shown that in vitro treatment of cells with TGF- $\beta$ induces regulatory cells that are more $(21,29,31,63)$ or less $(64)$ similar to naturally occurring Tregs. Thus, our results confirm previous observations on the importance of TGF- $\beta$ in oral tolerance and extend those observations to include the differentiation of antigen-specific Foxp $3^{+} \mathrm{CD}^{+}$Tregs in vivo upon oral administration of antigen.

The importance of TGF- $\beta$ in the generation of $\mathrm{CD}^{2} 5^{+} \mathrm{Foxp}^{+}$ Tregs in the periphery contrasts with the fact that naturally occurring Tregs can be generated in the absence of TGF- $\beta 1$ (65). Thus, although peripherally generated and thymic-derived naturally occurring Tregs have essentially the same phenotype and functional characteristics, they differ in the TGF- $\beta$ requirement for their generation. TGF- $\beta$ appears to have a role in the homeostasis of both naturally occurring and peripherally generated $\mathrm{CD}^{+} \mathrm{CD} 25^{+} \mathrm{Foxp}^{+}$Tregs (66-68). It is likely that a similar situation occurs for IL-2. IL-2 is not needed for the thymic generation of naturally occurring Tregs $(22,69,70)$ but is required for the peripheral maintenance and function of naturally occurring Tregs and probably for the peripheral induction of Tregs $(22,69)$. It is evident now that Foxp $3^{+} \mathrm{CD} 25^{+}$Tregs can be of thymic or peripheral origin and that additional factors are needed for the peripheral generation of Tregs that are not necessary for the generation of naturally occurring thymic-derived Tregs.

The fact that conventional immunization protocols lead to the generation of Tregs is of significance. Since, before i.p. immunization, naive OVA-specific T cells that will become Tregs cannot be distinguished from those that will become Th2 cells, it remains to be determined whether generation of Tregs versus that of effector $T$ cells is a stochastic process or some microenvironmental conditions promote the development of one cell type over the other. The fact that mucosal administration of antigen promotes the development of Tregs with very little Th2 differentiation favors the second possibility.

\section{Methods}

Mice. The T/B monoclonal mice (17/9 DO11.10 RAG1-/-) bearing monoclonal populations of $\mathrm{T}$ and $\mathrm{B}$ lymphocytes specific for chicken ovalbumin 323-339 and HA of influenza virus, respectively, were generated as previously described (32). BALB/c mice were purchased from Taconic or the Jackson Laboratory. BALB/c IL-10-/- mice were obtained from Donna Rennick

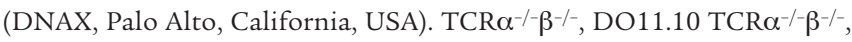
and 17/9 DO11.10 RAG1 $1^{-/-}$IL-10 $/ /-$mice (T/B monoclonal IL10 $0^{-/-}$mice) were all backcrossed into a BALB/c genetic background for more than 10 generations. All IL-10 $/-$ mice were kept on sulfamethoxazole $(400 \mathrm{mg} / \mathrm{l})$ and trimethoprim $(80 \mathrm{mg} / \mathrm{l})$ in their drinking water, except for the days in which they received OVA orally. All mice were bred and housed under specific pathogen-free conditions at the Skirball Institute animal facility. All procedures involving animals were approved by the New York University School of Medicine Institutional Animal Care and Use Committee.

Oral antigen administration, immunization, and airway challenge. Oral tolerance to OVA was induced by offering to the animals, ad libitum, a $1 \%$ OVA (grade II; Sigma-Aldrich) solution dissolved in drinking water for 5 consecutive days. The HA peptide (YPYDVPDYASLRS) was synthesized by ResGen. Crosslinked OVA-HA was prepared as previously described (32). Immunization with OVA-HA was performed i.p. with $100 \mu \mathrm{g}$ of OVA-HA 
adsorbed to $1 \mathrm{mg}$ of alum, 2 days after the end of the oral treatment. To induce airway inflammation, anesthetized mice were administered $10 \mu \mathrm{g}$ of OVA-HA i.n. in $50 \mu \mathrm{l}$ of PBS ( $25 \mu \mathrm{l}$ in each nostril) on days 14 and 21 after i.p. immunization. For TGF- $\beta$ neutralization, mice were injected i.p. with $2 \mathrm{mg}$ of the anti-TGF- $\beta$ monoclonal antibody 1D11 on 1 day before and 2 , 5 , and 8 days after the beginning of oral treatment.

$B A L$ collection and lung histology. Mice were deeply anesthetized by i.p. injection of anesthetic solution containing ketamine and xylazine. The tracheae were cannulated, and lungs were lavaged twice, once with $0.5 \mathrm{ml}$ and once with $1.0 \mathrm{ml}$ PBS. After total cell counting, cytospin preparations of the BAL cells were stained with DiffQuik (Baxter Dade AG), and differential cell counts were performed on 200 cells on the basis of morphology and staining characteristics. Student's $t$ test was used for statistical analysis.

Lungs were removed after BAL collection, perfused via the right ventricle with $10-\mathrm{ml}$ saline to remove residual blood, fixed with phosphate-buffered formalin, and embedded in paraffin. Tissue sections were stained with $\mathrm{H} \& \mathrm{E}$ to determine cellular inflammation or with PAS/ hematoxylin for evaluation of mucus-producing cells.

Serum and BAL antibodies. Total and HA-specific antibodies in serum or BAL samples were quantified by ELISA as described (32). Purified and biotinylated antibodies to Ig isotypes and standard purified immunoglobulin isotypes were purchased from BD Biosciences - Pharmingen and CALTAG Laboratories. Serum titer was defined as the lowest dilution that rendered an $O D$ value higher than 0.1 after background subtraction.

FACS analysis. Single cell suspensions in staining buffer (PBS containing $2 \%$ fetal calf serum and $0.1 \% \mathrm{NaN}_{3}$ ) were incubated for 45 minutes at $4{ }^{\circ} \mathrm{C}$ with the antibody cocktails. Samples were analyzed in a FACSCalibur instrument (BD). FITC-labeled and biotin-labeled HA peptides were purchased from ResGen. Peanut agglutinin-FITC and peanut agglutinin-biotin were purchased from Vector Laboratories. The remaining antibodies were purchased from BD Biosciences - Pharmingen and CALTAG Laboratories.

Cytokine production ex vivo. Cytokine production was analyzed ex vivo by intracellular staining. Briefly, cells were stimulated with 1- $\mu$ M OVA 323339 peptide for 4 hours. During the last 2 hours, cells were incubated with monensin (Sigma-Aldrich) to inhibit secretion. Cells were then surface stained with FITC-labeled KJ1-26 and PerCP-labeled anti-CD4 antibodies, fixed, permeabilized, stained with PE-labeled anti-IL-4 antibodies, and analyzed in a FACSCalibur.

Cell purification and transfer. $\mathrm{CD} 4^{+} \mathrm{CD} 25^{+}$and $\mathrm{CD} 4^{+} \mathrm{CD} 25^{-}$lymphocytes were purified from spleen and $\mathrm{mLN}$ cells by magnetic sorting using Miltenyi Biotec reagents and VarioMACS apparatus as described (22). Cell purity was checked by FACS analysis. The $\mathrm{CD} 25^{+}$purified fraction contained no more than $3 \% \mathrm{CD}^{+}{ }^{+} \mathrm{CD} 25^{-}$contamination. Purified CD25- cells contained $0.5-2 \%$ of CD25 $5^{\text {low }}$ cells and no CD2 $25^{\text {high }}$ cells. $3-5 \times 10^{5}$ purified cells were injected i.v. into recipient mice. In some experiments, $\mathrm{CD} 4^{+} \mathrm{CD} 25^{+}$and $\mathrm{CD} 4^{+} \mathrm{CD} 25^{-}$ cells were sorted in a MoFlo apparatus at the NYU Sorting Facility.

$R N A$ analysis. For quantitative mRNA expression analysis, $\mathrm{CD} 4^{+} \mathrm{CD} 25^{-}$and $\mathrm{CD} 25^{+}$cells were purified using either magnetic sorting or MoFlo sorting as described (22). RNA was extracted from samples using TRIzol (Invitrogen Corp.), and cDNA was synthesized by standard procedures. The expression of Foxp3, CTLA-4, IL-4, IFN- $\gamma$, and $\beta$-actin was determined by quantitative real-time PCR. Primers for Foxp3, CTLA-4, and $\beta$-actin were as described (22). Other primer sequences are as follows: IL-4: ACAGGAGAAGGGACGCCATG and GCAGCTTATCGATGAATCCA; IFN- $\gamma$ : GCTTTGCAGCTCTTCCTCAT and TCTTCCACATCTATGCCACTTG; TGF- $\beta$ : CTGCTGACCCCCACTGATA and GCTGAATCGAAAGCCCTGTA; SMAD2: CCGGCTGAACTGTCTCCTAC and ATAGTATGCGATTGAACACCAGAATG; IL-10: TCCCCTGTGAAAATAAGAGCA and TGGCCTTGTAGACACCTTGG; and IL-5: AGCAATGAGACGATGAGGC and ACACTTCTCTTTTTGGCGGT.

In vitro suppression assay. $\mathrm{CD} 4^{+} \mathrm{CD} 25^{-}$and $\mathrm{CD} 25^{+}$cells from $\mathrm{T} / \mathrm{B}$ monoclonal mice as well as fresh $\mathrm{BALB} / \mathrm{C} \mathrm{CD} 4^{+} \mathrm{CD} 25^{-}$and $\mathrm{CD} 25^{+}$cells were purified using magnetic sorting. Proliferation assays were set up in 96-well round bottom plates and contained, per well, the following: $2 \times 10^{4}$ responder cells $\left(\mathrm{CD} 4^{+} \mathrm{CD} 25^{-} \mathrm{BALB} / \mathrm{c}\right.$ cells); $4 \times 10^{4} \mathrm{APCs}$ (mitomycin C-treated spleen cells from TCR $\alpha \beta$-deficient BALB/c mice); and anti-CD3 antibody at a concentration of $0.5 \mathrm{mg} / \mathrm{ml}$. Putative suppressor cells were cocultured at responder/suppressor ratios of 1.0:1.0, 1.0:0.3, and 1.0:0.1. Proliferation was determined by adding ${ }^{3} \mathrm{H}$-thymidine on the third day of culture and determining incorporation 6 hours later.

\section{Acknowledgments}

Work in the J.J. Lafaille laboratory is supported by the NIH/ National Institute of Allergy and Infectious Diseases, the National Multiple Sclerosis Society, and the Dana-Goldsmith Foundation. D. Mucida was a recipient of a predoctoral fellowship from Coordenaçao de Aperfeiçoamento de Pessoal de Nivel Superior, Brazil. D. Mucida would like to thank Ana M.C. de Faria, Nelson M. Vaz, and A.C. Keller for very helpful discussions and suggestions.

Received for publication January 18, 2005, and accepted in revised form April 19, 2005.

Address correspondence to: Juan J. Lafaille or Maria A. Curotto de Lafaille, New York University Medical Center, Departments of Pathology and Medicine, Skirball Institute of Biomolecular Medicine, 540 First Avenue, New York, New York 10016, USA. Phone: (212) 263-1489; Fax: (212) 263-5711; E-mail: lafaille@saturn.med. nyu.edu (J.J. Lafaille). Phone: (212) 263-1469; Fax: (212) 263-5711; E-mail: curotto@saturn.med.nyu.edu (M.A. Curotto de Lafaille).
1. Vaz, N.M., et al. 2003. The conservative physiology of the immune system. Braz. J. Med. Biol. Res. 36:13-22.

2. Faria, A.M.C., and Weiner, H.L. 1999. Oral tolerance: mechanisms and therapeutic applications. Adv. Immunol. 73:153-264.

3. Wu, H.Y., and Weiner, H.L. 2003. Oral tolerance. Immunol. Res. 28:265-284.

4. Mayer, L., and Shao, L. 2004. Therapeutic potential of oral tolerance. Nat. Rev. Immunol. 4:407-419.

5. Chen, Y., et al. 1995. Peripheral deletion of antigen-reactive $\mathrm{T}$ cells in oral tolerance. Nature. 376:177-180.

6. Gutgemann, I., Fahrer, A.M., Altman, J.D., Davis, M.M., and Chien, Y.H. 1998. Induction of rapid T cell activation and tolerance by systemic presentation of an orally administered antigen. Immunity. 8:667-673.
7. McMenamin, C., McKersey, M., Kuhnlein, P., Hunig, T., and Holt, P.G. 1995. Gamma delta T cells down-regulate primary IgE responses in rats to inhaled soluble protein antigens. J. Immunol. 154:4390-4394.

8. Alpan, O., Bachelder, E., Isil, E., Arnheiter, H., and Matzinger, P. 2004. 'Educated' dendritic cells act as messengers from memory to naive T helper cells. Nat. Immunol. 5:615-622.

9. Van Houten, N., and Blake, S.F. 1996. Direct measurement of anergy of antigen-specific $\mathrm{T}$ cells following oral tolerance induction. J. Immunol. 157:1337-1341.

10. Zhang, X., Izikson, L., Liu, L., and Weiner, H.L. 2001. Activation of CD25(+)CD4(+) regulatory T cells by oral antigen administration. J. Immunol. 167:4245-4253.

11. Hauet-Broere, F., et al. 2003. Functional CD25- and CD25+ mucosal regulatory $\mathrm{T}$ cells are induced in gut-draining lymphoid tissue within $48 \mathrm{~h}$ after oral antigen application. Eur. J. Immunol. 33:2801-2810.

12. Chen, Y., and Ma, Y. 2002. Roles of cytotoxic Tlymphocyte-associated antigen- 4 in the inductive phase of oral tolerance. Immunology. 105:171-180.

13. Fowler, S., and Powrie, F. 2002. CTLA-4 expression on antigen-specific cells but not IL-10 secretion is required for oral tolerance. Eur. J. Immunol. 32:2997-3006.

14. Thorstenson, K.M., and Khoruts, A. 2001. Generation of anergic and potentially immunoregulatory CD25(+)CD4 T cells in vivo after induction of peripheral tolerance with intravenous or oral antigen. J. Immunol. 167:188-195.

15. Unger, W.W., et al. 2003. Early events in peripheral regulatory $\mathrm{T}$ cell induction via the nasal mucosa. 
J. Immunol. 171:4592-4603.

16. Dubois, B., et al. 2003. Innate CD4+CD25+ regulatory $\mathrm{T}$ cells are required for oral tolerance and inhibition of CD8+ T cells mediating skin inflammation. Blood. 102:3295-3301.

17. Ostroukhova, M., et al. 2004. Tolerance induced by inhaled antigen involves CD4(+) T cells expressing membrane-bound TGF- $\beta$ and FOXP3. J. Clin. Invest. 114:28-38. doi:10.1172/JCI200420509.

18. Faria, A.M., et al. 2003. Oral tolerance induced by continuous feeding: enhanced up-regulation of transforming growth factor-beta/interleukin-10 and suppression of experimental autoimmune encephalomyelitis. J. Autoimmun. 20:135-145.

19. Lafaille, J.J., Nagashima, K., Katsuki, M., and Tonegawa, S. 1994. High incidence of spontaneous autoimmune encephalomyelitis in immunodeficient anti-myelin basic protein $\mathrm{T}$ cell receptor transgenic mice. Cell. 78:399-408.

20. Apostolou, I., and von Boehmer, H. 2004. In vivo instruction of suppressor commitment in naive $\mathrm{T}$ cells. J. Exp. Med. 199:1401-1408.

21. Cobbold, S.P., et al. 2004. Induction of foxP3+ regulatory $\mathrm{T}$ cells in the periphery of $\mathrm{T}$ cell receptor transgenic mice tolerized to transplants. J. Immunol. 172:6003-6010.

22. Curotto de Lafaille, M.A., Lino, A.C., Kutchukhidze, N., and Lafaille, J.J. 2004. CD25- T cells generate $\mathrm{CD} 25+\mathrm{Foxp} 3+$ regulatory $\mathrm{T}$ cells by peripheral expansion. J. Immunol. 173:7259-7268.

23. Stock, P., et al. 2004. Induction of T helper type 1-like regulatory cells that express Foxp3 and protect against airway hyper-reactivity. Nat. Immunol. 5:1149-1156.

24. Chen, C., Lee, W.H., Yun, P., Snow, P., and Liu, C.P. 2003. Induction of autoantigen-specific Th2 and $\operatorname{Tr} 1$ regulatory $\mathrm{T}$ cells and modulation of autoimmune diabetes. J. Immunol. 171:733-744.

25. Sundstedt, A., O'Neill, E.J., Nicolson, K.S., and Wraith, D.C. 2003. Role for IL-10 in suppression mediated by peptide-induced regulatory $\mathrm{T}$ cells in vivo. J. Immunol. 170:1240-1248.

26. Vieira, P.L., et al. 2004. IL-10-secreting regulatory $\mathrm{T}$ cells do not express Foxp3 but have comparable regulatory function to naturally occurring CD4+CD25+ regulatory T cells. J. Immunol. 172:5986-5993.

27. Bynoe, M.S., Evans, J.T., Viret, C., and Janeway, C.A., Jr. 2003. Epicutaneous immunization with autoantigenic peptides induces $T$ suppressor cells that prevent experimental allergic encephalomyelitis. Immunity. 19:317-328.

28. Chen, Y., Kuchroo, V., Inobe, J., Hafler, D.A., and Weiner, H.L. 1994. Regulatory T cell clones induced by oral tolerance: suppression of autoimmune encephalomyelites. Science. 265:1237-1240.

29. Chen, W., et al. 2003. Conversion of peripheral CD4+CD25- naive T cells to CD4+CD25+ regulatory $\mathrm{T}$ cells by TGF-beta induction of transcription factor Foxp3. J. Exp. Med. 198:1875-1886.

30. Fantini, M.C., et al. 2004. Cutting edge: TGF-beta induces a regulatory phenotype in CD $4+C D 25-T$ cells through Foxp 3 induction and down-regulation of Smad7. J. Immunol. 172:5149-5153.

31. Park, H.B., Paik, D.J., Jang, E., Hong, S., and Youn, J. 2004. Acquisition of anergic and suppressive activities in transforming growth factor-betacostimulated CD4+CD25- T cells. Int. Immunol. 16:1203-1213.

32. Curotto de Lafaille, M.A., et al. 2001. Hyper immunoglobulin $\mathrm{E}$ response in mice with monoclonal populations of B and T lymphocytes. J. Exp. Med. 194:1349-1359.

33. Murphy, K.M., Heimberger, A.B., and Loh, D.Y. 1990. Induction by antigen of intrathymic apoptosis of CD4+ CD8+ $\mathrm{TCR}^{\text {lo }}$ thymocytes in vivo.
Science. 250:1720-1723.

34. Mombaerts, P., et al. 1992. RAG-1-deficient mice have no mature $\mathrm{B}$ and $\mathrm{T}$ lymphocytes. Cell. 68:869-877.

35. Russo, M., et al. 2001. Suppression of asthma-like responses in different mouse strains by oral tolerance. Am. J. Respir. Cell Mol. Biol. 24:518-526.

36. Russo, M., et al. 1998. Prevention of lung eosinophilic inflammation by oral tolerance. Immunol. Lett. 61:15-23.

37. Bottomly, K., et al. 1989. A monoclonal antibody to murine CD45R distinguishes CD4 T cell populations that produce different cytokines. Eur. J. Immunol. 19:617-623.

38. Sakaguchi, S., Sakaguchi, N., Asano, M., Itoh, M., and Toda, M. 1995. Immunologic self-tolerance maintained by activated T cells expressing IL-2 receptor alpha-chains (CD25). Breakdown of a single mechanism of self-tolerance causes various autoimmune diseases. J. Immunol. 155:1151-1164.

39. Read, S., Malmstrom, V., and Powrie, F. 2000. Cytotoxic T lymphocyte-associated antigen 4 plays an essential role in the function of CD25(+)CD4(+) regulatory cells that control intestinal inflammation. J. Exp. Med. 192:295-302.

40. Annacker, O., et al. 2001. CD25+ CD4+ T cells regulate the expansion of peripheral CD4 $\mathrm{T}$ cells through the production of IL-10. J. Immunol. 166:3008-3018.

41. Hori, S., Nomura, T., and Sakaguchi, S. 2003. Control of regulatory $T$ cell development by the transcription factor Foxp3. Science. 299:1057-1061.

42. Fontenot, J.D., Gavin, M.A., and Rudensky, A.Y. 2003. Foxp 3 programs the development and function of CD4(+)CD25(+) regulatory T cells. Nat. Immunol. 4:330-336.

43. Khattri, R., Cox, T., Yasayko, S.A., and Ramsdell, F. 2003. An essential role for Scurfin in CD4(+)CD25(+) T regulatory cells. Nat. Immunol. 4:337-342.

44. Piccirillo, C.A., and Shevach, E.M. 2004. Naturallyoccurring CD4+CD25+ immunoregulatory T cells: central players in the arena of peripheral tolerance. Semin. Immunol. 16:81-88.

45. Read, S., and Powrie, F. 2001. CD4(+) regulatory T cells. Curr. Opin. Immunol. 13:644-649.

46. Curotto de Lafaille, M.A., and Lafaille, J.J. 2002. $\mathrm{CD} 4(+)$ regulatory $\mathrm{T}$ cells in autoimmunity and allergy. Curr. Opin. Immunol. 14:771-778.

47. Weiner, H.L. 2001. Oral tolerance: immune mechanisms and the generation of Th3-type TGFbeta-secreting regulatory cells. Microbes Infect. 3:947-954.

48. Mowat, A.M. 2003. Anatomical basis of tolerance and immunity to intestinal antigens. Nat. Rev. Immunol. 3:331-341.

49. Cohn, L., Tepper, J.S., and Bottomly, K. 1998. IL-4independent induction of airway hyperresponsiveness by Th2, but not Th1, cells. J. Immunol. 161:3813-3816.

50. Takaoka, A., et al. 2001. A critical role for mouse CXC chemokine(s) in pulmonary neutrophilia during Th type 1-dependent airway inflammation. J. Immunol. 167:2349-2353.

51. Sawicka, E., et al. 2003. Inhibition of Th1- and Th2mediated airway inflammation by the sphingosine 1-phosphate receptor agonist FTY720. J. Immunol. 171:6206-6214.

52. Moore, K.W., de Waal Malefyt, R., Coffman, R.L., and O'Garra, A. 2001. Interleukin-10 and the interleukin-10 receptor [review]. Annu. Rev. Immunol. 19:683-765.

53. Samsom, J.N. 2004. Regulation of antigen-specific regulatory T-cell induction via nasal and oral mucosa. Crit. Rev. Immunol. 24:157-177.

54. Mattingly, J.A., and Waksman, B.H. 1978. Immuno- logic suppression after oral administration of antigen. I. Specific suppressor cells formed in rat Peyer's patches after oral administration of sheep erythrocytes and their systemic migration. J. Immunol. 121:1878-1883.

55. Richman, L.K., Chiller, J.M., Brown, W.R., Hanson, D.G., and Vaz, N.M. 1978. Enterically-induced immunological tolerance. I. Induction of suppressor $\mathrm{T}$ cells by intragastric administration of soluble proteins. J. Immunol. 212:2429-2435.

56. Zhang, X., Izikson, L., Liu, L., and Weiner, H.L. 2001. Activation of CD25(+)CD4(+) regulatory T cells by oral antigen administration. J. Immunol. 167:4245-4253.

57. Kobets, N., Kennedy, K., and Garside, P. 2003. An investigation of the distribution of antigen fed in tolerogenic or immunogenic forms. Immunol. Lett. 88:147-155.

58. Rizzo, L.V., et al. 1999. IL-4 and IL-10 are both required for the induction of oral tolerance. J. Immunol. 162:2613-2622.

59. Akbari, O., DeKruyff, R.H., and Umetsu, D.T. 2001. Pulmonary dendritic cells producing IL-10 mediate tolerance induced by respiratory exposure to antigen. Nat. Immunol. 2:725-731.

60. Miller, A., Lider, O., Roberts, A.B., Sporn, M.B., and Weiner, H.L. 1992. Suppressor T cells generated by oral tolerization to myelin basic protein suppress both in vivo and in vitro immune response by the release of transforming growth factor beta after antigen-specific triggering. Proc. Natl. Acad. Sci. U. S. A. 89:421-425.

61. Fukaura, H., et al. 1996. Induction of circulating myelin basic protein and proteolipid protein-specific transforming growth factor-beta1-secreting Th3 $\mathrm{T}$ cells by oral administration of myelin in multiple sclerosis patients. J. Clin. Invest. 98:70-77.

62. Barone, K.S., Tolarova, D.D., Ormsby, I., Doetschman, T., and Michael, J.G. 1998. Induction of oral tolerance in TGF-beta 1 null mice. J. Immunol. 161:154-160.

63. Walker, M.R., et al. 2003. Induction of FoxP3 and acquisition of $\mathrm{T}$ regulatory activity by stimulated human CD4+CD25- T cells. J. Clin. Invest. 112:1437-1443. doi:10.1172/JCI200319441.

64. Zheng, S.G., Gray, J.D., Ohtsuka, K., Yamagiwa, S., and Horwitz, D.A. 2002. Generation ex vivo of TGF-beta-producing regulatory $\mathrm{T}$ cells from CD4(+)CD25(-) precursors. J. Immunol. 169:4183-4189.

65. Piccirillo, C.A., et al. 2002. CD4(+)CD25(+) regulatory $\mathrm{T}$ cells can mediate suppressor function in the absence of transforming growth factor beta 1 production and responsiveness. J. Exp. Med. 196:237-246.

66. Huber, S., et al. 2004. Cutting edge: TGF-beta signaling is required for the in vivo expansion and immunosuppressive capacity of regulatory CD4+CD25+ T cells. J. Immunol. 173:6526-6531.

67. Schramm, C., et al. 2004. TGFbeta regulates the CD4+CD25+ T-cell pool and the expression of Foxp3 in vivo. Int. Immunol. 16:1241-1249.

68. Peng, Y., Laouar, Y., Li, M.O., Green, E.A., and Flavell, R.A. 2004. TGF-beta regulates in vivo expansion of Foxp3-expressing CD4+CD25+ regulatory $\mathrm{T}$ cells responsible for protection against diabetes. Proc. Natl. Acad. Sci. U. S. A. 101:4572-4577.

69. Furtado, G.C., Curotto de Lafaille, M.A., Kutchukhidze, N., and Lafaille, J.J. 2002. Interleukin 2 signaling is required for CD4(+) regulatory $\mathrm{T}$ cell function. J. Exp. Med. 196:851-857.

70. Antov, A., Yang, L., Vig, M., Baltimore, D., and Van Parijs, L. 2003. Essential role for STAT5 signaling in CD25+CD4+ regulatory $\mathrm{T}$ cell homeostasis and the maintenance of self-tolerance. J. Immunol. 171:3435-3441. 